other hand, does not have regions capable of strong intermolecular bonding [there is presumably intramolecular hydrogen bonding as in anthracene-picric acid (Herbstein \& Kaftory, 1975)] and thus fits without difficulty into a linear channel.

A somewhat similar structural situation has recently been reported for the ion-radical salt (TMTTF) $)_{1.3}(\text { TCNQ) })_{2}$ (Kistenmacher, Phillips, Cowan, Ferraris, Bloch \& Poehler, 1976) (TMTTF is 4,4',5,5'tetramethyl- $\Delta^{2,2^{\prime}}$-bis-1,3-dithiole and TCNQ is $7,7,8,8$ tetracyano- $p$-quinodimethane). However, many features of the diffraction patterns from (TMTTF $)_{1.3}(\mathrm{TCNQ})_{2}$ differ from those we have encountered.

The overall structural resemblance among these three compounds suggests that they can be formulated in

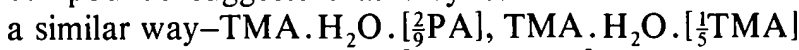
and (TMTTF).(TCNQ) $)_{2} \cdot[0 \cdot 3 \mathrm{TMTTF}]$, where the square brackets indicate the enclathrated molecules and the rest of the formula the framework structure.

All computations were carried out on the IBM $370 / 158$ computer at Caltech with the $C R Y M$ system of programs (Duchamp, Trus \& Westphal, 1969). We thank Dr Sten Samson for help with the measurements and Mrs Jean Westphal for help with programming. FHH is indebted to REM for his hospitality during sabbatical leave at Caltech.

\section{References}

Alcala, R. \& Martínez-Carrera, S. (1972). Acta Cryst. B28, 1671-1677.

Domenicano, A., Vaciago, A. \& Coulson, C. A. (1975). Acta Cryst. B31, 221-234.

Duchamp, D. J. \& Marsh, R. E. (1969). Acta Cryst. B25, $5-19$.

Duchamp, D. J., Trus, B. L. \& Westphal, J. (1969). Unpublished results.

Dunitz, J. D. \& White, J. D. N. (1973). Acta Cryst. A29, 93-94.

Herbstein, F. H. \& Kaftory, M. (1975). Acta Cryst. B32, 387-396.

Kistenmacher, T. J., Phillips, T. E., Cowan, D. O., Ferraris, J. P., Bloch, A. N. \& Poehler, T. O. (1976). Acta Cryst. B 32, 539-547.

Mo, F. \& Adman, E. (1975). Acta Cryst. B31, 192-198.

Sherfinski, J. S. \& Marsh, R. E. (1973). Acta Cryst. B29, 192-198.

Trueblood, K. N., Goldish, E. \& Donohue, J. (1961). Acta Cryst. 14, 1009-1017.

\title{
Structure and Charge Distribution of Oxamide as Determined from High-Order X-ray Data*
}

\author{
By G. DE WiTh AND S. HARKEMA \\ Chemical Physics Laboratory, Twente University of Technology, PO Box 217, Enschede, The Netherlands
}

(Received 3 December 1976; accepted 24 January 1977)

\begin{abstract}
The crystal structure and electronic charge distribution of oxamide (oxalic acid diamide, $\mathrm{C}_{2} \mathrm{~N}_{2} \mathrm{O}_{2} \mathrm{H}_{4}$ ) have been determined at $293 \mathrm{~K}$ by X-ray methods. The structural results of Ayerst \& Duke IActa Cryst. (1954), 7 , $588-590 \mid$ have been confirmed. High-order data [up to $(\sin \theta) / \lambda=1 \cdot 15 \AA^{-1}$ ] were collected. A clear indication of bonding features is obtained. The effect of data cut-off on the difference density map has been investigated.
\end{abstract}

\section{Introduction}

Although three earlier X-ray determinations have been performed for the triclinic form of oxamide (Misch \& van der Wijk, 1938; Romers, 1953; Ayerst \& Duke, 1954), none is accurate enough to show an indication of bonding features in the resulting difference-Fourier

\footnotetext{
* Part of this research has been carried out under the auspices of the Foundation for Fundamental Research on Matter by Electrons and X-rays (FOMRE), and with aid from the Netherlands Organization for Advancement of Pure Research (ZWO).
}

map. At present, however, it is possible to obtain X-ray results which do show reliable bonding features (see, e.g., Stevens \& Hope, 1975). A determination of the charge distribution was therefore carried out by means of X-ray methods.

\section{Experimental}

Oxamide crystals were grown from formamide by slow evaporation of a saturated solution kept at $363 \mathrm{~K}$. Frequently the crystals showed twinning las was expected 


\section{Table 1. General information}

Here and in the following tables least-squares standard deviations are given in parentheses.

$\begin{array}{lrll}a & 3.618(1) \AA & V & 87.51 \AA^{3} \\ b & 5.180(1) & d_{c} & 1.671 \mathrm{~g} \mathrm{~cm}^{-3} \\ c & 5.651(1) & \mu(\text { Mo } K(x) & 1.39 \mathrm{~cm}^{-1} \\ \alpha & 83.77(1)^{\circ} & Z & 1 \\ \beta & 113.97(1) & \text { Space group } & P \overline{1} \\ \gamma & 114.94(1) & & \end{array}$

$\begin{array}{lcccccc}\text { Refinement } & n & n_{s} & R(\%) & R_{w}(\%) & S & \text { Scale } \\ \text { Full-angle } & 2200 & 1936 & 6.2 & 5.8 & 3.99 & 38.55(0.09) \\ \text { High-order } & 1308 & 1074 & 11.1 & 4.2 & 1.49 & 37.98(0 \cdot 27)\end{array}$

$R=\Sigma \Delta F / \Sigma F_{o}: \Delta F=\left|F_{o}-F_{c}\right|$

$R_{w}=\left|\Sigma w \Delta F^{2} / \Sigma w F_{o}^{2}\right|^{1 / 2} ; w=1 / \sigma^{2}\left(F_{v}\right)$

$S=\left[\sum w \Delta F^{2} /(n-m)\right]^{1 / 2} ; n=$ number of reflexions, $m=$ number of parameters

$n_{s}=$ number of significant reflexions $\left|F_{o}>2 \sigma\left(F_{t}\right)\right|$

(Romers, 1953)|. A crystal of approximate dimensions $0.2 \times 0.2 \times 0.4 \mathrm{~mm}$ was used for the measurements.

The crystal was mounted on a Philips PW 1100 computer-controlled automatic diffractometer (Mo $K \alpha$ radiation, $\lambda=0.7107 \AA$, flat graphite monochromator, scintillation counter, pulse-height discriminator) (Hornstra \& Vossers, 1973).

Preliminary measurements at low temperature showed an unacceptable increase in mosaic spread. However, at room temperature a sufficient number of high-order data could be obtained, because of the relatively small thermal motion (see Table 4). Hence the measurements were made at $293 \mathrm{~K}$. This temperature was stable within $1 \mathrm{~K}$.

Reflexions were measured through the whole sphere up to $s=(\sin \theta) / \lambda=1.15 \AA^{-1}\left(\theta=55^{\circ}\right)$. The $\omega / 2 \theta$ step-scanning technique at a rate of $0.02^{\circ} \mathrm{s}^{-1}$, a step size of $0.03^{\circ}$ and a scan width of $(2.7+0.5 \tan \theta)^{\circ}$ were used throughout. The detector aperture was chosen as $3.0^{\circ}$ horizontally and $1.5^{\circ}$ vertically.

Cell constants (Table 1) were determined by a leastsquares procedure on the angular coordinates of $25 \mathrm{ac}$ curately centred reflexions. Since the diffraction symmetry is $\bar{l}$. space group $P I$ as well as $P \bar{l}$ is possible. A second harmonic powder test (Dougherty \& Kurtz, 1976) gave a signal less than $10^{-3}$ of the signal of $\alpha$ quartz. Hence, in accordance with Ayerst \& Duke (1954), the centrosymmetric space group $P \overline{1}$ was chosen.

\section{Data treatment}

During the measurements the three reference reflexions showed only small random fluctuations. Consequently no rescaling of measured data was performed. Net intensities were calculated from the step-scan profiles according to the algorithm of Larsen \& Lehmann (1974).
Absorption correction was carried out with the program $A C X R$ (Harkema, 1976) and a $6 \times 6 \times 6$ Gaussian quadrature (Margenau \& Murphy, 1957). The description of the crystal was given in terms of its seven rational boundary planes (Coppens, Leiserowitz \& Rabinovich, 1965). The calculated transmission factors ranged from 0.960 to $0.978 \mathrm{I} \mu=1.39 \mathrm{~cm}^{-1}$ (International Tables for X-ray Crystallography, 1974)l.

All reflexions were measured at least four times. From the different measurements for each reflexion a weighted average was calculated. The weights used in averaging were chosen as inverse counting statistics variances.

Variances of reflexions were calculated following the procedure proposed by McCandlish, Stout \& Andrews (1975). Taking into account data scaling and instrumental instability they derived the following formula: $\sigma^{2}(I)=K^{2} T+S^{2}(K) I_{o}^{2}+K^{2} P^{2} I_{o}^{2}$, where $I$ is the real net intensity, $T$ the total number of counts, $I_{o}$ the observed net intensity, $K$ the scaling factor $(I=$ $K I_{0}$; in this case $K$ is always $\left.1 \cdot 0\right), S^{2}(K)$ the variance of $K$, and $P$ the instability constant. $P$ was calculated from three reference reflexions $\left(P 1=2.4 \times 10^{-3}, P 2=2 \cdot 1\right.$ $\times 10^{-3}, P 3=4.9 \times 10^{-3}$ ) resulting in an average $P$ value of $3.1 \times 10^{-3}$ Icompare this with the value of 2.8 $\times 10^{-3}$ for our diffractometer reported earlier (de With \& Feil, 1976)l. The variance of $K$ showed no systematic time dependence owing to the highly consistent behaviour of the reference reflexions. Therefore an average value was used $\left[S^{2}(K)=2.3 \times 10^{-4}\right]$. Now $S^{2}(K) I_{o}^{2}$ and $K^{2} P^{2} I_{o}^{2}$ can be taken together. $\mid S^{2}(K)+$ $\left.K^{2} P^{2}\right|^{1 / 2}=1.5 \times 10^{-2}$; this value is directly comparable with that of $N$ in the weighting scheme often used: $\sigma^{2}(I)=T+N^{2} I_{o}^{2}$, with $N$ typically chosen between $1 \times$ $10^{-2}$ and $5 \times 10^{-2}$.

It has been shown for the case of pyrazine (de With \& Feil, 1976) that the variances derived in this way properly represent the random errors in the net intensity of each reflexion.

The internal consistency index $R_{I}$, defined as $R_{I}=$ $\sum|I-\bar{I}| / \Sigma I$, where $I$ is the intensity of a reflexion and $I$ the corresponding weighted average of each reflexion, was $1.3 \%$. Lorentz-polarization and monochromator corrections were performed in the usual way. Although a normal distribution in $I$ seems more justified, we assumed a normal distribution in the structure factor $F$ for calculating $\sigma(F)$ from $\sigma(I)$. No numerical integration is required in this case (Rees, 1976). The total number of independent reflexions was 2200 , of which 1936 had an intensity greater than twice their standard deviation.

\section{Refinement}

Full-matrix least-squares refinements have been carried out by a local modification of ORFLS (Busing, Martin \& Levy, 1962). The function minimized was $\Sigma w\left(\left|F_{o}\right|\right.$ 
Table 2. High-order positional and thermal parameters

For non-hydrogen atoms positional parameters are $\times 10^{5}$ and thermal parameters are $\times 10^{4}$. The anisotropic temperature factor used was: $\exp \left[-2 \pi^{2}\left(h^{2} a^{* 2} U_{11}+k^{2} b^{* 2} U_{22}+l^{2} c^{* 2} U_{33}+2 h k a^{*} b^{*} U_{12}+2 h l a^{*} c^{*} U_{13}+2 k l b^{*} c^{*} U_{23}\right)\right]$.

For hydrogen atoms positional and thermal parameters are $\times 10^{3}$. The isotropic temperature factor used was: $\exp \left(-\pi^{2} U_{11} \sin ^{2} \theta / \lambda^{2}\right)$.

\begin{tabular}{lccll} 
& $x$ & \multicolumn{1}{c}{$y$} & \multicolumn{1}{c}{$z$} & \multicolumn{1}{c}{$U_{11}$} \\
$\mathrm{C}$ & $-100(18)$ & $49328(8)$ & $36481(6)$ & $248(2)$ \\
$\mathrm{N}$ & $366(25)$ & $72319(9)$ & $23724(8)$ & $451(3)$ \\
$\mathrm{O}$ & $-484(23)$ & $27993(9)$ & $28308(8)$ & $472(3)$ \\
$\mathrm{H}(1)$ & $23(5)$ & $874(3)$ & $324(2)$ & $67(4)$ \\
$\mathrm{H}(2)$ & $102(3)$ & $735(2)$ & $896(2)$ & $22(2)$
\end{tabular}

$\begin{array}{ccccc}U_{22} & U_{33} & U_{12} & U_{13} & U_{23} \\ 152(1) & 147(1) & 105(1) & 104(1) & 26(1) \\ 191(1) & 193(1) & 184(2) & 183(2) & 70(1) \\ 194(1) & 206(1) & 195(2) & 190(2) & 43(1)\end{array}$

$\left.-k\left|F_{c}\right|\right)^{2}, k$ being the scale factor, $\left|F_{o}\right|$ the observed structure factor, and $\left|F_{c}\right|$ the calculated structure factor. The weight $w$ for each reflexion was taken to be $\sigma^{-2}$, where $\sigma$ is the standard deviation of $\left|F_{o}\right|$. The summation is over all independent reflexions (Hirshfeld \& Rabinovich, 1973).

The data as given by Ayerst \& Duke (1954) served as starting parameters. After a few cycles of refinement the positions of the $\mathrm{H}$ atoms could be estimated from a difference-Fourier map. Atomic scattering factors for the $\mathrm{C}, \mathrm{N}$ and $\mathrm{O}$ atoms were taken from International Tables for X-ray Crystallography (1974). For $\mathrm{H}$ the scattering factor given by Stewart, Davidson \& Simpson (1965) was used. The introduction of an isotropic secondary extinction factor (Larson, 1969) gave no significant improvement. The value of the extinction parameter was very small, and therefore the correction has been omitted in the subsequent analysis.

High-order (HO) refinement, for reflexions with $s>$ $0.85 \AA^{-1}$, has been carried out. The $\mathrm{H}$ atom parameters were kept fixed at their values resulting from the corresponding full-angle (FA) refinement. Relevant information about the refinements is given in Table 2. It may be useful to mention that $R$ values drop several per cent if nonsignificant reflexions are excluded from the refinement. $R_{w}$ values do not change substantially and $S$ values increase. Final HO positional and thermal parameters are given in Table 2.*

\section{Crystal and molecular structure}

A general view of the hydrogen-bonding scheme is given in Fig. 1 (ORTEP, Johnson, 1965). A stereoscopic view of the molecular packing, drawn with the aid of the program STER (van de Waal, 1973) is presented in Fig. 2. The molecular packing has been discussed by Ayerst \& Duke (1954).

Bond distances and angles were derived from the $\mathrm{HO}$ positional parameters with ORFFE (Busing, Martin \& Levy, 1964) and are given in Table 3.

\footnotetext{
* A list of structure factors has been deposited with the British Library Lending Division as Supplementary Publication No. SUP 32466 (15 pp.). Copies may be obtained through The Executive Secretary. International Union of Crystallography, 13 White Friars, Chester $\mathrm{CH} 1 \mathrm{INZ}$. England.
}

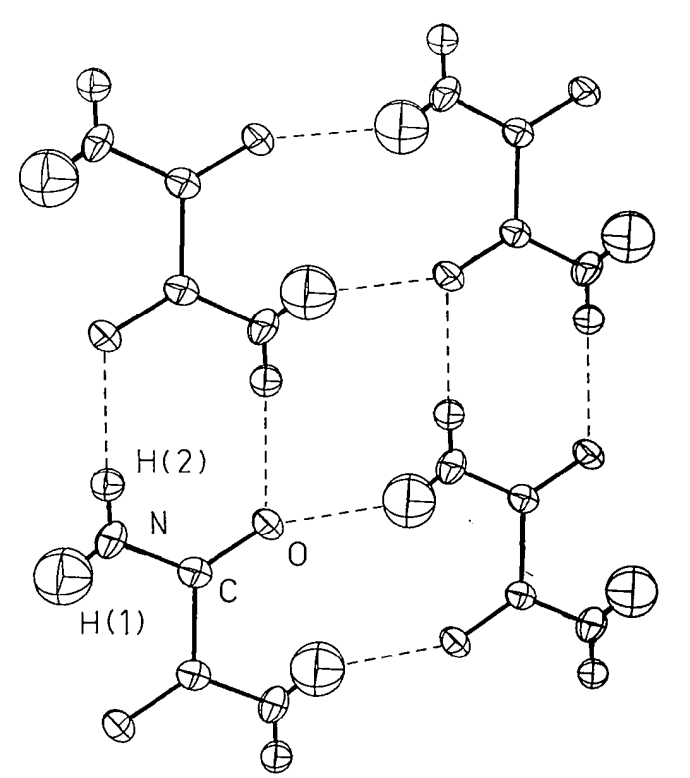

Fig. 1. Molecular structure and hydrogen-bonding scheme.

For comparison, the results obtained by Ayerst \& Duke (1954) are also quoted. The frame of the molecule (containing the heavy atoms) is planar within experimental accuracy. The intercept equation of the best plane is $-88.270 x+1.725 y+0.275 z=1.0$, where $x, y$ and $z$ are fractional coordinates along the crystal axes. The angle between the plane of the molecule and the $b c$ plane is $(0.65 \pm 0.04)^{\circ}$.

The $\mathrm{H}$ atoms are also located in the plane of the frame [distance to the plane: $\mathrm{H}(1) 0.022, \mathrm{H}(2) 0.007$ $\AA ̊ l$, as has also been noted by Romers (1953). This result is contrary to the assertion of Scott \& Wagner (1959). They justify non-planarity of the $\mathrm{H}$ atoms by strong torsional modes of the $\mathrm{NH}_{2}$ group. Their statement that this is required by $\mathrm{X}$-ray results is certainly not correct.

The root-mean-square displacements (r.m.s.d.'s) on principal axes of the heavy atoms are given in Table 4. Two components are approximately equal. The third component has roughly twice this magnitude. For all three atoms this component is roughly perpendicular to the molecular plane. 

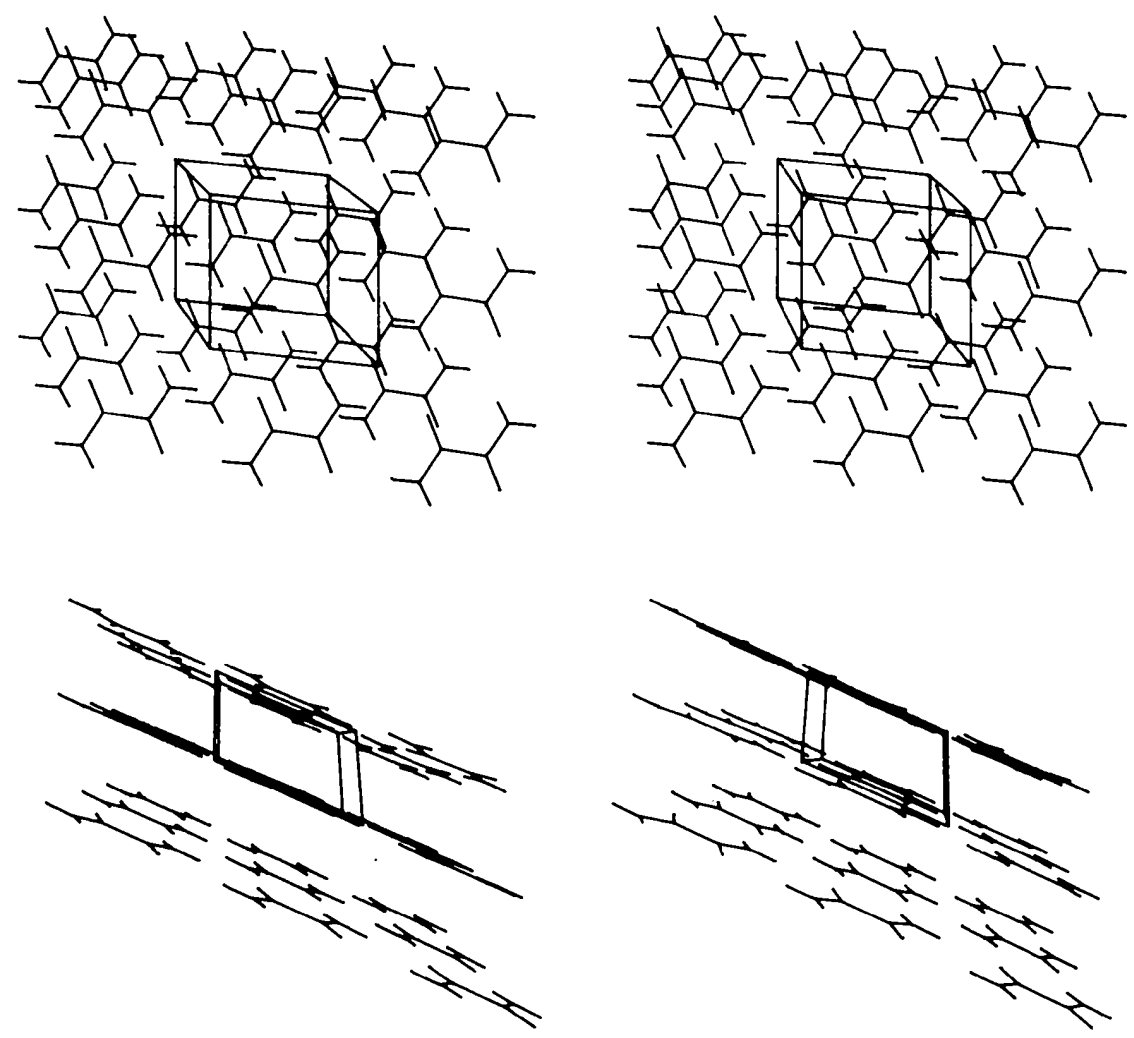

Fig. 2. General view of the molecular packing.

Table 3. Bond distances $(\AA)$ and angles $\left(^{\circ}\right)$

$\begin{array}{llc} & \text { This work } & \text { Ayerst \& Duke (1954) } \\ \mathrm{C}-\mathrm{C} & 1.5340(5) & 1.542(6) \\ \mathrm{C}-\mathrm{N} & 1.3211(5) & 1.315(4) \\ \mathrm{C}-\mathrm{O} & 1.2359(4) & 1.243(4) \\ \mathrm{N}-\mathrm{H}(1) & 0.93(1) & - \\ \mathrm{N}-\mathrm{H}(2) & 0.84(1) & - \\ & & \\ \mathrm{C}-\mathrm{C}-\mathrm{O} & 120 \cdot 26(4) & 119.5(3) \\ \mathrm{C}-\mathrm{C}-\mathrm{N} & 114.47(4) & 114.8(3) \\ \mathrm{O}-\mathrm{C}-\mathrm{N} & 125 \cdot 28(4) & 125.7(3) \\ \mathrm{C}-\mathrm{N}-\mathrm{H}(1) & 117.0(8) & - \\ \mathrm{C}-\mathrm{N}-\mathrm{H}(2) & 120.6(6) & - \\ \mathrm{H}(1)-\mathrm{N}-\mathrm{H}(2) & 122.2(1.1) & -\end{array}$

Table 4. Root-mean-square displacements $(\AA)$ along the principal axes

$\begin{array}{cccc} & U_{1} & U_{2} & U_{3} \\ \mathrm{C} & 0.1079(5) & 0.1162(5) & 0.1576(6) \\ \mathrm{N} & 0.1146(5) & 0.1229(5) & 0.2124(8) \\ \mathrm{O} & 0.1068(5) & 0.1310(5) & 0.2174(7)\end{array}$

A rigid-bond test, as discussed recently by Hirshfeld (1976), was performed. The r.m.s.d.'s along the $\mathrm{C}=\mathrm{O}$ and $\mathrm{C}-\mathrm{N}$ bonds are given in Table 5 . The average difference is 2.5 times the combined standard deviation for the r.m.s.d.'s derived from the HO data. The corre-
Table 5. Root-mean-square displacements (§) along the bonds, to verify the rigid-bond hypothesis

$Z_{A, B}$ denotes the r.m.s.d. of atom $A$ along the vector from $A$ to $B$.

\begin{tabular}{cccccc} 
& \multicolumn{2}{c}{$Z_{A, B}(\AA)$} & \multicolumn{2}{c}{$Z_{B, A}(\AA)$} \\
$A$ & $B$ & FA & HO & FA & HO \\
$\mathrm{C}$ & $\mathrm{N}$ & $0.1200(5)$ & $0.1161(5)$ & $0.1160(5)$ & $0.1151(5)$ \\
$\mathrm{C}$ & $\mathrm{O}$ & $0.1127(5)$ & $0.1104(5)$ & $0.1084(5)$ & $0.1078(5)$
\end{tabular}

sponding figure for the r.m.s.d.'s derived from the FA data is 5.9. In spite of the use of the spherical-atom refinement the rigid-bond test is well satisfied.

\section{Charge distribution}

Before considering the charge distribution the following points have to be made. The average standard deviation in the difference-Fourier map $(\Delta \rho)$ is estimated as 0.019 e $\AA^{-3}$, with $\sigma(\Delta \rho)=\left[\Sigma \sigma^{2}\left(F_{o}\right)\right]^{1 / 2} / k V$. It should be kept in mind that the standard deviation at special points, e.g. the centre of symmetry, may be higher because of the compilation of errors (Rees, 1976).

The optimum $s$ value for the data cut-off when calculating $\Delta \rho$ was determined in the same way as in the case of pyrazine (de With, Harkema \& Feil, 1976). The value chosen was $0.85 \AA^{-1}$ (see Fig. 3). The correspond- 


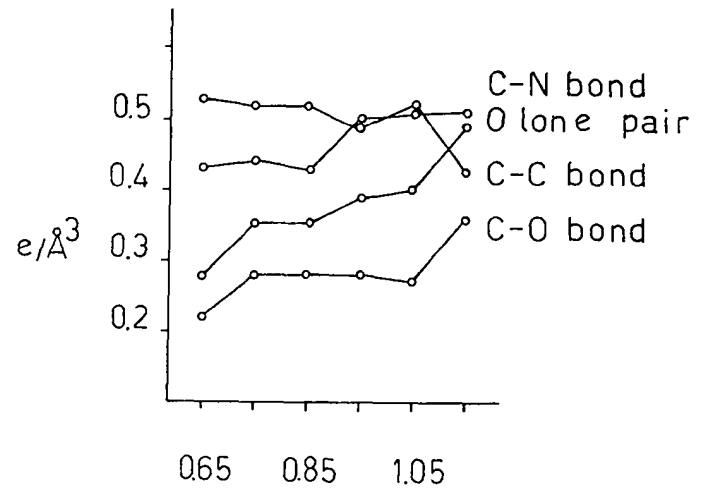

$(\sin \theta) / \lambda$

Fig. 3. Convergence of the value of $\Delta \rho$ in bond and lone-pair regions as a function of the $(\sin \theta) / \lambda$ cut-off value. ing resolving power is $0.42 \AA$ [ for discussion see Rees (1976)l.

The scale factor for the difference-Fourier-map calculation was determined in separate refinements with the data cut-off values as enumerated in Fig. 3. In these refinements the positional and thermal parameters were kept fixed at their $\mathrm{HO}$ values. The different scale factors obtained in this way were virtually the same. The maximum deviation from the $\mathrm{HO}$ scale factor, which should be a fair estimate of the true scale factor (Ruysink \& Vos, 1974), is about $0.5 \%$.

With the HO parameters a difference-Fourier map was calculated in the plane of the molecule. The Fourier calculation was performed by the program $S P F T$ (van de Waal, 1975). All reflexions with $s \leq 0.85 \AA^{-1}$ were used. The scattering factor for $\mathrm{H}$ used here was taken from International Tables for X-ray Crystallography (1974). The $\Delta \rho$ map is shown in Fig. 4.

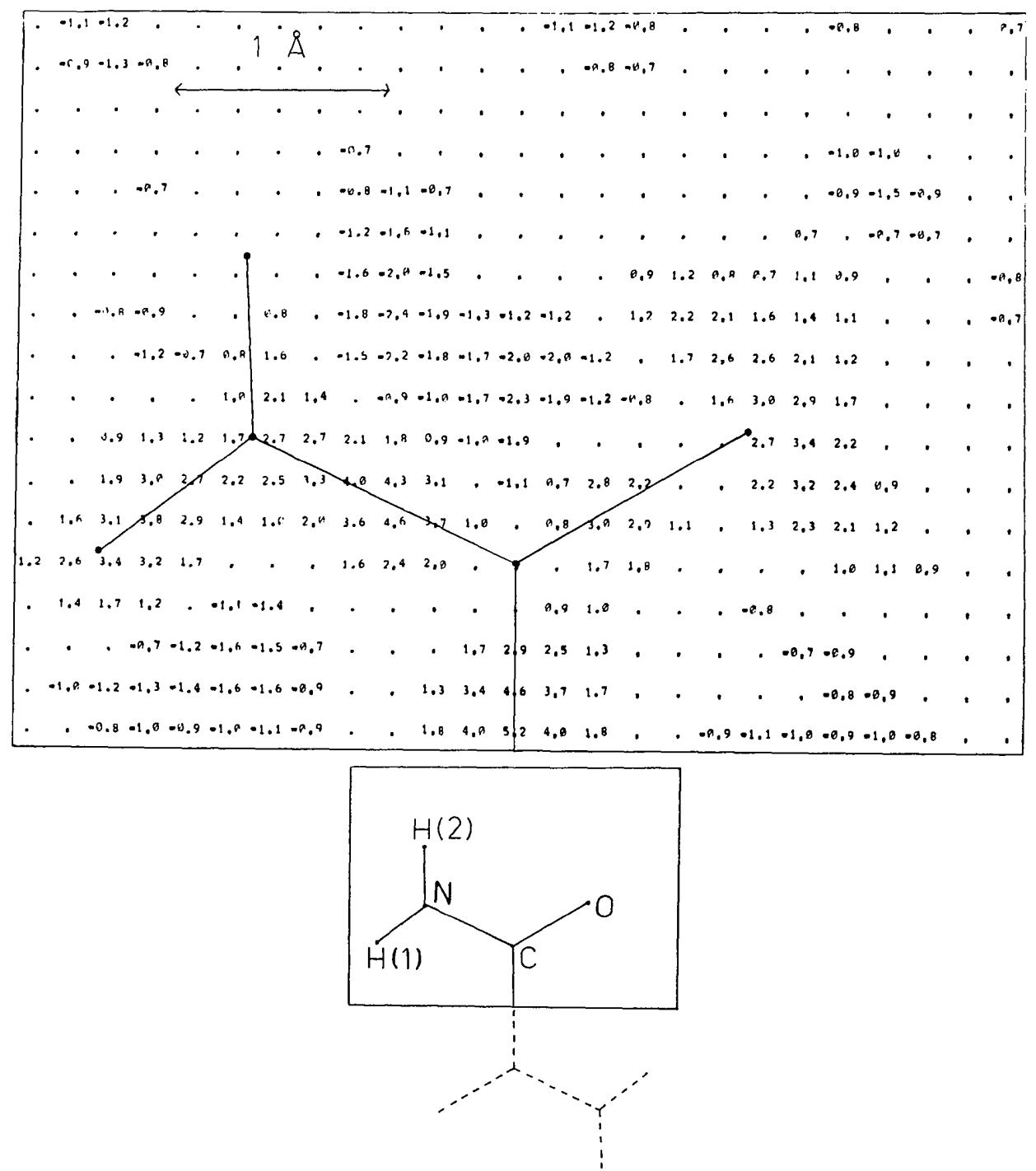

Fig. 4. Difference-Fourier map in the plane of the molecule (units: $0 \cdot 1$ e $\AA^{-3}$ ). 
A clear indication of the bonding features is observed. The lone-pair density of the $\mathrm{O}$ atom is represented by a broad single maximum, although theoretically one expects two maxima. The same situation occurs around atom $\mathrm{O}(2)$ in cyanuric acid (Verschoor \& Keulen, 1971; Coppens \& Vos, 1971) and atom $O(2)$ in $a$-glycine (Almlöf, Kvick \& Thomas, 1973). The difference density in the $\mathrm{C}=\mathrm{O}$ bond is relatively low, as compared with the $\mathrm{C}-\mathrm{C}$ and $\mathrm{C}-\mathrm{N}$ bonds. This fact now seems well established, since the same feature occurs in the $X-N$ maps of several compounds (see, e.g., Datt \& Ozerov, 1975; Coppens, 1975). The height of $\Delta \rho$ in the $\mathrm{C}-\mathrm{C}$ and $\mathrm{C}-\mathrm{N}$ bonds fits well in the range usually observed (Datt \& Ozerov, 1975; Coppens, 1975). There seems to be no explanation for the lack of bonding density in the $\mathrm{N}-\mathrm{H}(2)$ bond.

Finally, it should be mentioned that the quantitative picture might change upon correcting the data for thermal diffuse scattering (TDS), although the qualitative features probably remain the same (see, e.g., de With, Harkema \& Feil, 1976). In this case TDS correction could not be performed because neither elastic constants nor reliable lattice dynamical calculations are available.

Many thanks are due to $\mathrm{Mr}$ J. Boeijsma for growing the crystals and to Dr J. P. Dougherty of North American Philips, for performing the second harmonic powder test.

\section{References}

Almlöf, J., Kvick, A. \& Thomas, J. O. (1973). J. Chem. Phys. 59, 3901-3910.

Ayerst, E. M. \& Duke, J. R. C. (1954). Acta Crvst. 7, 588590.

Busing, W. R., Martin, K. O. \& Levy, H. A. (1962). ORFLS. Report ORNL-TM-305. Oak Ridge National Laboratory, Tennessee.

Busing, W. R., Martin, K. O. \& Levy, H. A. (1964). ORFFE. Report ORNL-TM-306. Oak Ridge National Laboratory, Tennessee.

Coppens, P. (1975). MTP International Review of Science: Phi'sical Chemistru' Series 2. Vol. 11, edited by J. M. ROBERTSON. London: Butterworths.

Coppens, P., Leiserowitz, L. \& Rabinovich, D. (1965). Acta Cryst. 18, 1035-1038.

Coppens, P. \& Vos, A. (1971). Acta Crvst. B27, 146-158.
Datr, I. D. \& Ozerov, R. P. (1975). Zh. Strukt. Khim. 16, $509-535$.

Dougherty, J. P. \& Kurtz, S. K. (1976). J. Appl. Cryst. 9, 145-158.

HaRkema, S. (1976). $A C X R$. An absorption correction program for use in connexion with the PW 1100 diffractometer.

Hirshfeld, F. L. (1976). A cta Cry'st. A 32, 239-244.

Hirshfeld, F. L. \& Rabinovich, D. (1973). Acta Cry'st. A29. 510-513.

Hornstra, J. \& Vossers, H. (1973). Philips Tech. Rev. 33, 61-73.

International Tab'les for X-ray' Cry'stallography' (1974). Vol. IV. Birmingham: Kynoch Press.

Johnson, C. K. (1965). ORTEP. Report ORNL-3794. Oak Ridge National Laboratory. Tennessee.

Larsen, F. K. \& Lehmann, M. S. (1974). Acta Cry'st. A30, 580-584.

Larson, A. C. (1969). Crystallographic Computing, edited by F. R. A hmed, pp. 291-294. Copenhagen: Munksgaard.

McCandlish, L. E., Stout, G. H. \& Andrews, L. C. (1975). Acta Cry'st. A 31, 245-249.

Margenau, H. \& Murphy, G. M. (1957). The Mathematics of Physics and Chemistry, pp. 479-481. Princeton: Van Nostrand.

MISCH, L. \& VAN DER WIJK, A. J. A. (1938). C.R. Soc. Phy's. Hist. Nat. Genève, 55, 96.

Rees, B. (1976). Acta Cry'st. A 32 483-488.

Romers, C. (1953). Acta Cry'st. 6, 429.

Ruysink, A. F. J. \& Vos, A. (1974). Acta Cry'st. A30, 503506.

Scott, T. A. JR \& Wagner, E. L. (1959). J. Chem. Phys. 30, 465-469.

Stevens, E. D. \& Hope, H. (1975). Acta Cryst. A31, 494498.

Stewart, R. F., Davidson, E. R. \& Simpson, W. T. (1965). J. Chem. Phy's. 42, 3175-3187.

Verschoor, G. C. \& K fulen. E. (1971). Acta Crist. B27, $134-145$.

WAAL. B. W. vaN DE (1973). STER. A Fortran program for drawing crystal structures. Progress Report No. 12. Chemical Physics Laboratory, Twente Univ. of Technology, Enschede, The Netherlands.

WAAL, B. W. VAN DE (1975). SPFT. Slant Plane Fourier Transform Program. Progress Report No. 14. Chemical Physics Laboratory, Twente Univ. of Technology, Enschede, The Netherlands.

With, G. DE \& FelL, D. (1976). Acta Crist. A32, 10111012.

With, G. De, Harkema, S. \& Ffil, D. (1976). Acta Cryst. B32, 3178-3184. 